Artigo

\title{
As contribuições da régua de cálculo linear na construção dos saberes e das práticas docentes
}

The contributions of the slide rule in the construction of knowledge and teaching practices

\author{
Las contribuciones de la regla de cálculo lineal en la construcción de conocimientos y \\ prácticas de enseñanza
}

\author{
Andressa Gomes dos Santos ${ }^{1}$ \\ (iD [0000-0003-1982-714X] \\ Adriana Nogueira de Oliveira ${ }^{2}$ \\ [0000-0003-1542-2452] \\ Ana Carolina Costa Pereira ${ }^{3}$ \\ (D) [0000-0002-3819-2381]
}

\begin{abstract}
Resumo
No Renascimento, com a expansão do comércio, vender produtos exigia uma resolução mais ágil de cálculos, o que acarretava na utilização de instrumentos matemáticos que facilitavam esses procedimentos. Um deles, bastante disseminado no século XVII, era conhecido como régua de cálculo. Dessa forma, este artigo tem o intuito de apresentar um estudo sobre a régua de cálculo linear, em particular, direcionando as reflexões acerca da construção de saberes e práticas docentes proporcionadas a partir da sua construção e da sua utilização em um curso de extensão universitária. Em relação aos procedimentos metodológicos, a pesquisa se caracteriza conforme a pesquisa-ação, tendo um cunho qualitativo, em que é possível, a partir do contexto real, se apresentar recursos para o desenvolvimento e reflexão que propiciam a ressignificação da prática educativa. A partir do curso, foi constatado que os participantes mobilizaram saberes fundamentais para formação da prática docente, sendo estes identificados pelos diferentes conhecimentos propostos nos estudos de Lee Shulman, o que enriquece o potencial da análise realizada. Dentre os conhecimentos que foram mobilizados, podemos destacar o conhecimento pedagógico e o da matéria do conteúdo desvelado pelos participantes do curso e percebido por meio da fala dos mesmos. Notou-se, assim, a importância desse tipo de abordagem de história e ensino de matemática para a formação de professores.
\end{abstract}

Palavras-chave: Saberes e práticas docentes. Régua de Cálculo linear. Interface entre história e ensino de matemática.

\begin{abstract}
In the Renaissance, with the expansion of trade, selling products required a more agile calculation resolution, which resulted in the use of mathematical instruments that facilitated these procedures. One, quite widespread in the 17th century, was known as a slide rule. Thus, this article aims to present a study on the linear slide rule, in particular, directing reflections on the construction of knowledge and teaching practices provided from its construction and use in a university extension course.

\footnotetext{
${ }^{1}$ andressa.gomes.santos06@aluno.ifce.edu.br, licenciada em Matemática, mestranda do Programa de PósGraduação em Ensino de Ciências e Matemática, Instituto Federal de Educação, Ciência e Tecnologia do Ceará, Fortaleza/Ceará/Brasil.

2 nogueira.oliveira@aluno.uece.br, pedagoga, mestranda do Programa de Pós-Graduação em Educação, Universidade Estadual do Ceará, Fortaleza/Ceará/Brasil.

${ }^{3}$ carolina.pereira@uece.br, doutora, docente, Universidade Estadual do Ceará, Fortaleza/Ceará/Brasil.
} 
Regarding the methodological procedures, the research is characterized according to the researchaction, having a qualitative nature, in which it is possible, from the real context, to present resources for the development and reflection that provide a new meaning for educational practice. From the course, it was found that the participants mobilized fundamental knowledge for the formation of teaching practice, which were identified by the different knowledge proposed in Lee Shulman's studies, which enriches the potential of the analysis performed. Among the knowledge that was mobilized, we can highlight the pedagogical and material knowledge of the content unveiled by the course participants and perceived through their speech. Thus, it was noted the importance of this type of approach to history and teaching of mathematics for teacher training.

Keywords: Teaching knowledge and practices; Slide rule; Interface between history and mathematics teaching.

\section{Resumen}

En el Renacimiento, con la expansión del comercio, la venta de productos requería una resolución de cálculo más ágil, lo que resultó en el uso de instrumentos matemáticos que facilitaron estos procedimientos. Una, bastante extendida en el siglo XVII, se conocía como regla de cálculo. Así, este artículo tiene como objetivo presentar un estudio sobre la regla de cálculo lineal, en particular, dirigiendo reflexiones sobre la construcción de conocimientos y prácticas docentes desde su construcción y uso en un curso de extensión universitaria. En cuanto a los procedimientos metodológicos, la investigación se caracteriza de acuerdo a la investigación-acción, teniendo un carácter cualitativo, en el que es posible, desde el contexto real, presentar recursos para el desarrollo y la reflexión que brinden un nuevo significado a la práctica educativa. A partir del curso, se encontró que los participantes movilizaron conocimientos fundamentales para la formación de la práctica docente, los cuales fueron identificados por los distintos conocimientos propuestos en los estudios de Lee Shulman, lo que enriquece el potencial del análisis realizado. Entre los conocimientos que se movilizaron, podemos destacar el conocimiento pedagógico y material del contenido desvelado por los participantes del curso y percibido a través de su discurso. Así, se señaló la importancia de este tipo de aproximaciones a la historia y la enseñanza de las matemáticas para la formación del profesorado.

Palabras claves: Enseñanza de conocimientos y prácticas; Regla de cálculo lineal; Interfaz entre la enseñanza de la historia y la matemática.

\section{Introdução}

A incorporação da história da matemática no ensino vem sendo tratada em diversos estudos no âmbito da educação matemática, como nos estudos de Bissi (2014); D’Ambrósio (2007); Miguel (1997) e Baroni, Teixeira e Nobre (2011). Essas pesquisas estão diretamente ligadas a como implementar a história ao ensino de matemática, tanto na sala de aula como na formação de professores de matemática.

Uma discussão sobre esse assunto está sendo realizada pelo grupo de estudo e pesquisa em História e Epistemologia na Educação Matemática (HEEMa), vinculado à Pontifícia Universidade Católica de São Paulo (PUCSP) e liderado pelo Prof. Fumikazu Saito, que busca aprofundar as reflexões das possíveis articulações entre história da matemática, ensino e as possibilidades pedagógicas desta. Em consonância com o HEEMa, o Grupo de Pesquisa em Educação e História da Matemática (GPEHM), da Universidade Estadual do Ceará (UECE), que tem como líder a Profa. Dra. Ana Carolina Costa Pereira, também faz discussões sobre a história da matemática aliada ao ensino de matemática, no qual se direcionam os 
estudos à construção de interfaces entre a história e o ensino de matemática ${ }^{4}$, não só relacionadas ao didático, como também ao pedagógico.

Nessa proposta, duas áreas estão relacionadas: a educação matemática e a história da matemática, pois, como possuem objetos de estudo, metodologias e procedimentos próprios, um diálogo deve ser estabelecido, resultando em atividades potencialmente didáticas para a formação do professor de matemática. Nesse contexto, Pereira e Saito (2019) ressaltam que a história da matemática pode ofertar recursos para o desenvolvimento de abordagens aliadas ao ensino de matemática, visto que trata o conhecimento matemático no seu processo de construção.

Nessa interface, é por meio do diálogo entre o historiador e o educador matemático que se estabelece um documento de estudo. Esse documento pode ser livros, tratados, cartas, manuscritos, minutas, assim como instrumentos, monumentos e máquinas (SAITO, 2015). Logo, o instrumento matemático é considerado como um meio de construir uma interface, na qual a teoria e a prática estão interligadas, pois esses artefatos trazem um saber-fazer de uma época.

Dentre os instrumentos matemáticos que podem estar na interface entre história e ensino de matemática, encontra-se a régua de cálculo linear, propagada entre os séculos XVI e XVII. Alguns autores fizeram estudos envolvendo essa temática, tais como Tanonaka (2008), Pipa (2014) e Alves (2019) ${ }^{5}$.

No estudo de Tanonaka (2008), a autora aborda a história que envolve a régua de cálculo sob um viés historiográfico tradicional perpassando pela vida do "criador", os estudos que ele desenvolvia e as réguas construídas por ele, a linear e a circular. Em particular, a autora analisa os textos de William Oughtred, The Circles of Proportion and The Horizontal Instrument (1633), New Artificial Gauging Lineor Rod (1633) e The Description and Use of the Double Horizontal Dial (1653), sem fazer nenhum vínculo do instrumento com o ensino de matemática.

Outra autora, que faz um estudo sobre a régua de cálculo, é a Pipa (2014). Ela propõe uma sequência didática envolvendo a régua de cálculo linear para o estudo das propriedades dos logarítmicos, enfocando, também, conteúdos como a caracterização das funções logarítmicas, a associação de logaritmos a progressões aritméticas e geométricas.

Já Alves (2019) desenvolveu um estudo por meio da construção de uma interface entre a história e o ensino de matemática, utilizando uma historiografia atualizada a partir da manipulação do instrumento círculos de proporção, também conhecido como régua de cálculo circular, descrito em The Circles of Proportion and the Horizontal Instrument (1633), do inglês William Oughtred (1574 - 1660).

Dessa forma, considera-se que um estudo utilizando esse artefato, sob uma historiografia atualizada, trará potencialidades didáticas e pedagógicas na formação do professor de matemática. Entretanto, outros elementos, além do conteúdo matemático, devem ser visualizados, como, por exemplo, os saberes docentes articulados na sua prática em sala de aula.

\footnotetext{
${ }^{4}$ Por construção de interfaces entre história e ensino de matemática, entende-se como um "[...] conjunto de ações e produções que promova a reflexão sobre o processo histórico da construção do conhecimento matemático para elaborar atividades didáticas que busquem articular história e ensino de matemática" (SAITO; DIAS, 2013, p. 92).

${ }^{5}$ Essa pesquisa foi realizada no dia 10 de março de 2020, na Biblioteca Digital Brasileira de Teses e Dissertações (BDTD), colocando a palavra-chave "régua de cálculo".
} 
No que se refere à relação entre os professores e os saberes que ensinam, estes se configuram como essenciais na prática dos professores e na configuração de sua identidade profissional, revelando, portanto, a importância de se voltar a atenção para esses saberes que estão diretamente relacionados com a aprendizagem discente e o desenvolvimento de novas práticas educativas que auxiliam alunos e professores.

Muitas são as pesquisas acerca dos conhecimentos adquiridos pelos professores ao longo de sua formação inicial e continuada. Nesse contexto, nascem estudos que tratam dos fundamentos da prática docente, criando-se, assim, a categoria saber docente, que surge para buscar conhecer a singularidade e a complexidade do exercício da atividade do professor (MONTEIRO 2001).

A afirmação da autora nos permite inferir que a categoria saber docente se apresenta como essencial, já que busca compreender os conhecimentos a partir da ação dos professores, evidenciando, dessa maneira, a necessidade de se voltar a atenção para essa categoria que representa a construção da relação do educador com a sua prática. Nas próximas seções deste trabalho, apresentaremos uma discussão mais ampla sobre os saberes docentes para que se possa compreender como estes fazem parte da ação dos professores.

Para este artigo, foram apresentadas as categorias propostas por Lee Shulman (1986). $O$ estudo desse autor considera a necessidade de se conhecer a relação dos professores com os conhecimentos específicos que ensinam, assim Shulman (1986) apresenta uma proposta na qual devemos pensar esses conhecimentos a partir de três categorias, sendo elas:: o conhecimento da matéria do conteúdo; o conhecimento pedagógico dos conteúdos e o conhecimento curricular. Contudo, a discussão a respeito desses conhecimentos será apresentada na terceira seção deste trabalho.

Estudos que alinhem os saberes docentes vinculados ao uso do instrumento matemático, em particular a régua de cálculo linear, podem trazer benefícios para a formação inicial do professor de matemática. Dessa forma, este artigo tem o intuito de apresentar os saberes construídos pelos participantes do curso de extensão universitária, oferecido pelo Laboratório de Matemática e Ensino (LABMATEN), da Universidade Estadual do Ceará (UECE). Adiante, será exposto como se constituiu o curso, para que se possa compreender a construção e o manuseio do instrumento matemático utilizado nesta pesquisa, que possibilitou a descoberta de novos conhecimentos pelos participantes do curso ofertado.

Para isso, este estudo foi elaborado e desenvolvido mediante a uma organização sistemática, que se busca apresentar ao leitor. Por isso, inicialmente, será exposto o caminho metodológico percorrido para a construção do artigo. Em seguida, é descrito o percurso histórico, no qual se teve o desenvolvimento da régua de cálculo linear, a fim de situar o instrumento historicamente e compreender um pouco sobre quais estudos estavam acontecendo na época, que poderiam ter contribuído para a sua construção.

Para fundamentar a pesquisa, é apresentada a categoria saber docente, pela qual se mostram os conhecimentos que os educadores devem dominar para o exercício da atividade docente. Por fim, são apontados os saberes emergidos a partir da construção e do manuseio da régua de cálculo linear, que se configura como um instrumento histórico que traz inúmeras contribuições para o ensino de matemática e para a formação de professores.

\section{Procedimentos metodológicos}

A presente pesquisa se traduz em um viés qualitativo, pois essa abordagem se baseia “[...] numa perspectiva que concebe o conhecimento como um processo socialmente 
construído pelos sujeitos nas suas interações cotidianas, enquanto atuam na realidade, transformando-a e sendo por ela transformados" (ANDRÉ, 2013, p. 97). Assim, esteve ao centro deste trabalho conhecer a realidade dos sujeitos inseridos nesta pesquisa, a fim de proporcionar aos mesmos o conhecimento dos conceitos construídos ao longo da história pela sociedade.

Além disso, a pesquisa se caracteriza como pesquisa-ação, pois a mesma nos possibilita perceber o contexto real a partir da reflexão dos aspectos que fazem parte da vivência no cotidiano dos sujeitos inseridos na pesquisa, como também contribui para que estes sujeitos, a partir da problematização de seu contexto, possam perceber e efetivar as mudanças necessários no exercício de sua prática, portanto a pesquisa-ação pode ser entendida como

[...] um processo investigativo de intervenção em que caminham juntas prática investigativa, prática reflexiva e prática educativa. Ou seja, a prática educativa, ao ser investigada, produz compreensões e orientações que são imediatamente utilizadas em sua própria transformação, gerando novas situações de investigação. (FIORENTINI e LORENZATO, 2007, p. 112-113).

A pesquisa-ação nos possibilita perceber dimensões que outros caminhos metodológicos não dariam conta, portanto esse é o tipo de pesquisa que permite uma percepção crítica dos achados, de modo a contribuir para ressignificação das práticas educativas, como também a construção de novos saberes a partir do diálogo e interação dos sujeitos inseridos em um mesmo contexto.

Contudo, é preciso esclarecer ainda que os dados analisados seguem a perspectiva dialética que "fornece bases para uma interpretação dinâmica e totalizante da realidade, já que estabelece que os fatos sociais não podem ser entendidos quando considerados isoladamente, abstraídos de suas influências políticas, econômicas, culturais etc.". (GIL, 1999 p, 32).

A partir disso, delimitamos os sujeitos de nossa pesquisa - alunos da licenciatura em matemática e professores de matemática. Desse modo, o curso foi intitulado "Construção da Régua de Cálculo Linear para o estudo de conceitos sobre multiplicação" no qual se disponibilizou 12 vagas sendo todas preenchidas, destas 11 participantes eram alunos da graduação e um professor de matemática da rede estadual de ensino. O curso ocorreu no Laboratório de Matemática e Ensino (LABMATEN), da Universidade Estadual do Ceará (UECE), em março de 2019.

Seu planejamento teve carga horária de 12h/a, as quais foram divididas em $6 \mathrm{~h} / \mathrm{a}$ presenciais e $6 \mathrm{~h} / \mathrm{a}$ a distância. Nesse período, os participantes realizaram atividades e responderam formulários on-line sobre o curso e os conhecimentos matemáticos que eles manipularam ou perceberam como potencialidade didática a partir da construção e utilização da régua de cálculo linear.

Os instrumentos de coleta de dados foram formulários on-line, disponibilizados na plataforma Google Formulários, relatórios das atividades, vídeos e áudios dos grupos que foram analisados sob a compreensão dialética. A partir dessa análise, também se utilizou das categorias propostas por Shulman (1986) acerca dos saberes docentes, identificando os conhecimentos que foram mobilizados na construção da régua de cálculo linear. 
Vale ressaltar que o estudo está aliado à literatura específica, estabelecendo-se um diálogo com os autores desse referencial teórico como: Martins (2019); Mendes e Soares (2019); Pereira (2015); Monteiro (2001); Shulman (1986), que tratam especificamente do campo dos elementos históricos que constituem a construção do instrumento matemático, identificado como régua de cálculo linear e pontuam os saberes docentes adquiridos pelos participantes do curso de extensão universitário por meio da construção e manuseio desse instrumento.

\section{Um breve panorama histórico acerca do desenvolvimento da régua de cálculo linear}

A Europa, entre os anos de 1450 e 1550, período do renascimento, despertou um interesse humanístico pelos antigos escritos e em relação às ciências, que estava relacionado à matemática e à valorização das artes manuais (SAITO, 2015). A régua de cálculo linear aparece citada em tratados desse período histórico e, no que diz respeito às ciências, havia uma busca por estudos de séculos passados.

O fato de as artes manuais e a matemática estarem em ascensão nesse período tem grande impacto na construção de instrumentos matemáticos, pois foi uma época na qual o comércio estava expandindo por conta das grandes navegações. Assim, os comerciantes precisavam realizar cálculos com mais rapidez e os marinheiros precisavam se localizar em alto mar. Dessa forma, houve a necessidade da construção de instrumentos que suprissem as necessidades (SAITO, 2014).

Com isso, alguns estudiosos se destacaram, tais como John Napier (1550 - 1617), Edmund Gunter (1581 - 1626) e William Oughtred (1574 - 1660), que colaboraram com o desenvolvimento de instrumentos que incorporam algum conhecimento matemático, seja para a resolução de operações aritméticas ou para medir distâncias, alturas e ângulos.

John Napier foi um estudioso que desenvolveu a ideia de logaritmos. De acordo com Mendes e Soares (2019), o desenvolvimento dos logaritmos de Napier se iniciou por um estudo de senos a partir de experimentações em que ele concluiu que o produto de dois senos poderia ser verificado facilmente, culminando em uma generalização para os números.

Apoiando-se nas ideias desenvolvidas com seus estudos, Napier publicou dois tratados sobre os logaritmos, o Mirifici Logarithmorum Canonis Descriptio, publicado em 1614, sobre a descrição dos logaritmos e outro sobre os conceitos envolvidos na construção dos logaritmos, o Mirifici Logarithmorum Canonis Constructio, publicado em 1619. Ambos viriam a ser uma peça importante para a matemática e para a vida das pessoas que necessitavam realizar contas com agilidade.

Além da construção dos logaritmos, Napier também desenvolveu um instrumento facilitador de cálculos matemáticos com base em somas de parcelas parciais baseadas em tábuas de multiplicação dispostas em barras (MARTINS, 2019). As Barras de Napier ou Ossos de Napier foram construídos com o intuito de simplificar as operações de multiplicação e divisão. Eles são descritos no tratado Rabdologiae, Seu Numerationis Per Virgulas Libri Duo: cum appendice de expeditíssimo Multiplicationes promptuario, quibus acessit e arithmeticea localis liber unus Rabdologiae, publicado em 1617. Segundo Martins e Pereira (2018, p. 160),

A obra é constituída de quatro livros. O Primeiro Livro descreve a construção e utilização das barras de números, conhecidas como barras Napier ou Ossos de Napier, pois era comum utilizar marfim em sua construção. No Segundo Livro, é apresentada a barra para cálculos geométricos. O terceiro livro, descreve a construção e utilização do tabuleiro mecânico, que é uma 
planificação das barras, com a finalidade de facilitar os cálculos. E o quarto contém os detalhes de construção e utilização do denominado do prontuário de multiplicação, conhecido, também, como ábaco de Napier. (MARTINS; PEREIRA, 2018, p. 160).

O tratado traz a descrição do instrumento matemático desenvolvido por Napier, explica como se deu a construção e como se manuseiam as barras para realização de operações como divisão, potenciação, radiciação e regras de três simples e compostas (MARTINS, 2019). Nessa publicação, ele não traz a explicação do motivo pelo qual há números invertidos nas barras de Napier (Figura 1).

Podemos ver, na Figura 1, a representação no plano das marcações que compõem as barras, "seu formato físico corresponde ao que atualmente denominamos prisma de base quadrada, contendo em suas faces quadrados divididos pela diagonal, nos quais serão inseridos números, de modo a permitir a realização de multiplicações, divisões, potenciações e radiciações". (MARTINS, 2019, p. 28).

Figura 1 - Representação no plano das marcações feitas nas Barras de Napier.

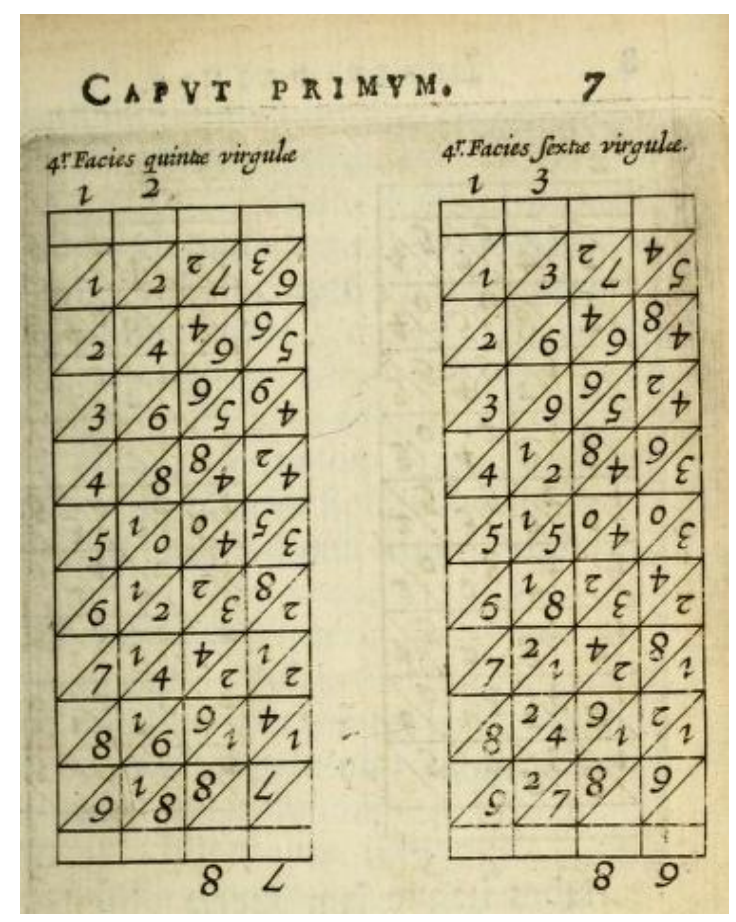

Fonte: Napier (1617, p. 6).

Outro estudioso que desenvolveu instrumentos matemáticos, como o Sector e a CrossStaff, foi Edmund Gunter, que teve uma contribuição significativa na construção da Régua de Cálculo de Oughtred, com o instrumento construído por ele, denominado Escala de Gunter (Figura 2). 
Figura 2 - Escala de Gunter.

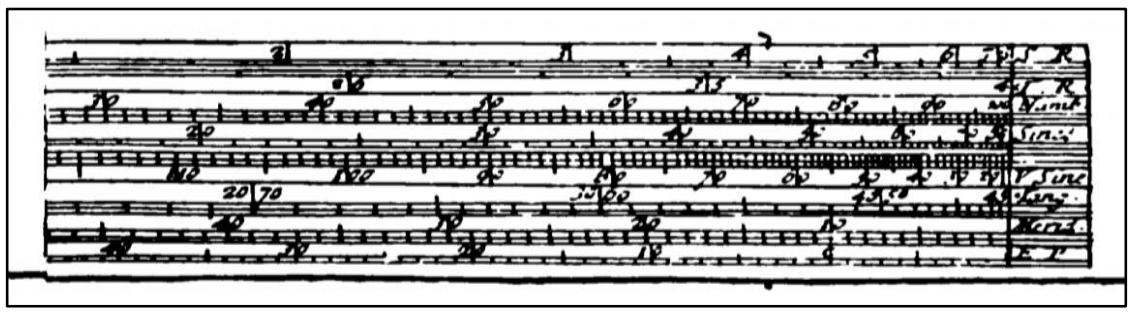

Fonte: Cajori (1909, p. 4).

Esse instrumento foi apresentado em uma publicação de 1620, chamada Canon triangulorum, sive tabulae sinuum et tangentium artificialium ad radium 10000,0000. $£$ ad scrupula prima quadrantes ${ }^{6}$ e sua utilização era feita com auxílio de um compasso posicionado nos números em que se desejava realizar as operações aritméticas, o resultado era obtido por meio das somas nas escalas logarítmicas.

A Escala de Gunter e o Sector foram instrumentos desenvolvidos anteriormente à construção da régua de cálculo linear, elaborada por William Oughtred e, diferente da Escala de Gunter, dispensa o uso do compasso para a realização das operações.

A régua de cálculo linear foi desenvolvida por William Oughtred, "um inventor independente da régua retilínea e o primeiro a propor o tipo circular" (CAJORI, 1909, p. 11). Ele utilizou os logaritmos para construir esse instrumento, além dessa, ele foi o estudioso que desenvolveu a versão circular da régua.

William Oughtred publicou sobre esse instrumento circular em 1632, na obra denominada "Circles of the Proportion and the Horizontal Instrument"7. Oughtred traz, na primeira parte, o instrumento círculos de proporção, em que ele "[...] trata de estudos matemáticos relacionados aos seus círculos de proporção e está dividido em 14 capítulos [...]" (ALVES, 2019, p. 36). Esse instrumento (Figura 3) continha círculos compostos por escalas logarítmicas que realizavam operações como multiplicação e divisão.

Figura 3 - Círculo de Proporção de Oughtred.



Fonte: Oughtred (1632, n. p.).

\footnotetext{
${ }^{6}$ Triângulos Canon, ou tabelas de senos e tangentes do logaritmo do raio 10000,0000 . E o primeiro minuto dos quadrantes (GUNTER, 1620, tradução nossa).

${ }^{7}$ Círculos da Proporção e o Instrumento Horizontal (OUGHTRED, 1632, tradução nossa).
} 
Na obra de 1632, não faz menção à régua de cálculo linear (Figura 4), mas Oughtred publicou, em 1633, "An addition into the use of the instrument called the circles of proportion" ${ }^{\prime \prime}$ que trazia, no final do documento, uma descrição da régua linear (CAJORI, 1916).

Figura 4 - Régua de Cálculo Linear.

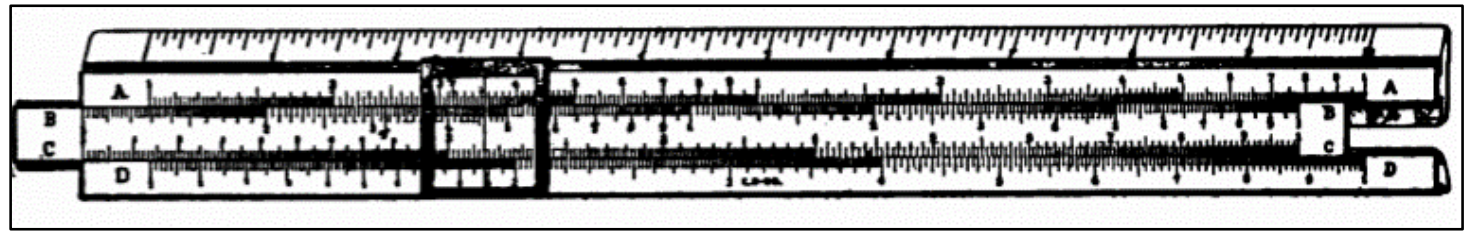

Fonte: Cajori (1909, p. 68).

Essa publicação foi incluída em "Circles of Proportion", como um volume sobre a régua de cálculo linear que "[...] apresentava além da construção da régua, aplicações para cálculo de triângulos, questões aritméticas e problemas sobre distâncias em relação ao sol e as estrelas". (PEREIRA, 2015, p. 50).

A régua de cálculo linear era composta por escalas logarítmicas, assim como a Escala de Gunter e continha uma régua móvel, dessa forma, não era necessário o uso do compasso, portanto, na régua de Oughtred, o manuseio é mais ágil para obter o resultado procurado, pois ela, por si só, já realizava cálculos por meio de soma e subtração de segmentos. (PEREIRA, 2015).

Diante do exposto, podemos inferir que a régua de cálculo linear é um instrumento histórico de importância incontestável e que pode ser utilizada nos dias atuais como mecanismo de auxílio docente no ensino da multiplicação.

\section{Sobre saberes, práticas e formação docente}

Ao longo das décadas, muitas mudanças têm ocorrido no cenário educacional. Diante desse fato, buscou-se um instrumento teórico que desse conta da complexidade dos moldes vigentes em nossa sociedade. Assim, criou-se a categoria saber docente, que busca identificar a relação dos professores com os saberes que ensinam. Para tanto, inúmeras pesquisas já foram realizadas acerca dessa categoria (SHULMAN, 1986; TARDIF, LESSARD, LAHAYE, 1991).

As pesquisas já realizadas mostram a percepção de que os trabalhos têm apresentado significado, mas não conseguem dar conta da singularidade da ação docente, logo, é importante destacar que, para trabalhar com os saberes docentes, faz-se necessário conhecer essa categoria que se encontra diretamente interligada à prática docente e aos processos formativos, destacando-se, dessa forma, a relevância do diálogo entre essas categorias que estruturam o conhecimento profissional.

Mesmo sendo constantes as discussões sobre essa temática, compreende-se que se trata de assunto que, embora de suma importância, ainda demanda estudos que viabilizem um diálogo mais amplo em torno dos professores e dos saberes que ensinam.

Entre os autores que têm voltado seus estudos para a categoria saber docente, podemos destacar os estudos realizados por Lee S. Shulman, psicólogo educacional americano, que tem realizado contribuições para o ensino. Neste trabalho, utilizaram-se as categorias propostas por Shulman (1986), que buscam compreender os diferentes conhecimentos que os professores dominam.

\footnotetext{
${ }^{8}$ Um acréscimo no uso do instrumento chamado círculos de proporção (OUGHTRED, 1632, tradução nossa).
} 
Shulman (1986) apresenta três categorias distintas para identificar os conhecimentos desenvolvidos pelos professores, sendo eles: o conhecimento da matéria do conteúdo; o conhecimento pedagógico dos conteúdos e o conhecimento curricular.

Monteiro (2001) apresenta uma breve explicação em relação às categorias destacadas por Shulman (1986). Para a autora, o conhecimento sobre a matéria do conteúdo diz respeito à organização do conhecimento por si na mente dos docentes.

Mas, para que se possa conhecer bem os conteúdos, é preciso ir além do conhecimento dos fatos, sendo necessário conhecer a estrutura da matéria que está dividida em: estrutura substantiva e estrutura sintática.

A estrutura substantiva é aquela na qual os conceitos básicos e princípios da disciplina estão organizados para incorporar os fatos. A estrutura sintática de uma disciplina é o conjunto de modos pelos quais verdade ou falsificabilidade, validade ou invalidade são estabelecidas. A sintaxe é um conjunto de regras para determinar o que é legítimo num domínio disciplinar e o que quebra as regras. (MONTEIRO 2001, p. 135).

O conhecimento pedagógico do conteúdo se refere a um segundo tipo de conhecimento do conteúdo, pois vai além do conhecimento da matéria e passa da dimensão do conhecimento da matéria para o assunto de ensinar, "inclui as formas mais comuns de representação das ideias, as analogias mais poderosas, as ilustrações, os exemplos, explicações e demonstrações, ou seja, os modos de representar e formular o assunto de forma a torná-lo compreensível para os outros" (MONTEIRO, 2001, p. 135).

O conhecimento curricular é o conhecimento sobre o currículo, um conjunto de estratégias elaboradas a partir das disciplinas com objetivo específico, dados e características que podem ser usados ou não para orientar o ensino.

Tendo destacado a importância dos saberes docentes para a consolidação da prática docente e para a configuração da identidade profissional, nesta sessão, buscou-se apresentar a relação que se estabelece entre os professores e os saberes que ensinam. Na próxima seção, serão expostos os saberes adquiridos por futuros docentes por meio da construção e do uso da régua de cálculo linear.

\section{Conhecendo o curso de extensão universitária na pesquisa}

O curso de extensão, intitulado Construção da régua de cálculo linear para o estudo de conceitos sobre multiplicação, teve o intuito de conhecer as possibilidades didáticas da régua de cálculo linear para o ensino de multiplicação e identificar, na sua construção e no seu manuseio, a operação de multiplicação e os conceitos matemáticos envolvidos. Para isso, realizamos a atividade em grupos de 3 pessoas, definindo seus papéis a partir de Cohen e Lotan (2017, p. 112):

Facilitador - Certifica-se de que todos obtenham a ajuda de que precisam para realizar a tarefa; é responsável por procurar respostas para as perguntas dentro do grupo; o professor só é consultado apenas se ninguém do grupo puder ajudar.

Verificador - Certifica-se de que todo mundo tenha completado seu relatório individual.

Relator - É responsável por organizar o relatório do grupo e sua apresentação para a turma. 
Gerenciador de Materiais (monitor) - É responsável por obter materiais e recursos e por retira-los adequadamente.

Controlador de tempo - É responsável por regular o tempo da atividade proposta.

Harmonizador - É responsável por resolver os possíveis conflitos que venham a existir no grupo.

O texto que foi utilizado para o auxílio da construção e manuseio foi produzido a partir do livro de Pereira (2015), que traz, além da construção da régua de multiplicação, a construção dos logaritmos e do artigo de Martins, Pereira e Fonseca (2016), que desenvolve a construção das escalas logarítmicas da régua. Além desse material, foram construídos dois cartões de atividades, um guia do relatório, um cartão de hipóteses e uma ficha de avaliação diária. Para melhor compreensão, definimos cada instrumento utilizado na atividade:

$\equiv$ Cartão recurso - Material que contém o texto base utilizado na atividade.

$\equiv$ Cartão de atividade - Material com a sequência didática ou as orientações para os participantes no desenvolvimento da atividade.

$\equiv$ Cartão de hipóteses - Material desenvolvido antes da aplicação do curso, que contém possíveis comportamentos dos participantes (saberes docentes) em relação à atividade.

$\equiv$ Ficha de avaliação diária - Documento disponibilizado ao participante no final de cada dia de curso, como forma de avaliar a aula e a postura do professor.

$\equiv$ Guia do relatório - Documento que serve como guia para os participantes escreverem o relatório de cada atividade.

A seguir, no quadro 1, apresenta-se o plano do curso de extensão aplicado.

Quadro 1 - Cronograma do curso.

\begin{tabular}{|c|c|c|}
\hline OBJETIVOS & CONTEÚDOS & $\mathrm{C} / \mathrm{H}$ \\
\hline $\begin{array}{l}\text { Para o discente: } \\
\equiv \text { Conhecer os instrumentos matemáticos } \\
\text { Barras de Napier, Escala de Gunter e as } \\
\text { réguas de cálculo, circular e, } \\
\text { principalmente, a linear como parte } \\
\text { constituinte da história no que se refere } \\
\text { à matemática do século XVII. } \\
\text { Para o docente: } \\
\equiv \text { Apresentar aos participantes um } \\
\text { conhecimento breve sobre o contexto } \\
\text { histórico da régua de cálculo linear. }\end{array}$ & $\begin{array}{l}\text { UNIDADE 1: Conhecendo um } \\
\text { pouco sobre o contexto histórico } \\
\text { da régua de cálculo linear } \\
1.1 \text { Panorama dos estudos } \\
\text { matemáticos sobre logaritmos e } \\
\text { alguns instrumentos de calcular. } \\
1.2 \text { Considerações sobre a régua } \\
\text { de cálculo linear. }\end{array}$ & $2 \mathrm{~h} / \mathrm{a}$ \\
\hline $\begin{array}{l}\text { Para o discente: } \\
\equiv \text { Estudar a construção e o manuseio da } \\
\text { régua de cálculo linear a partir do texto } \\
\text { disponibilizado. }\end{array}$ & $\begin{array}{l}\text { UNIDADE 2: Compreensão da } \\
\text { construção da régua de cálculo } \\
\text { linear } \\
2.1 \text { Estudo do texto que trata da } \\
\text { construção da régua de cálculo } \\
\text { linear, especificamente, das }\end{array}$ & $2 \mathrm{~h} / \mathrm{a}$ \\
\hline
\end{tabular}




\begin{tabular}{|c|c|c|}
\hline $\begin{array}{l}\text { Elencar os conceitos matemáticos } \\
\text { inerentes à construção da régua de } \\
\text { cálculo linear a partir do texto. } \\
\text { Para o docente: } \\
\text { Proceder para que os participantes } \\
\text { questionem, formulem e discutam sobre os } \\
\text { conhecimentos matemáticos incorporados } \\
\text { no instrumento por meio da leitura que trata } \\
\text { da construção da régua de cálculo linear. }\end{array}$ & $\begin{array}{l}\text { escalas logarítmicas da } \\
\text { multiplicação. } \\
\text { 2.2 Atividade sobre os elementos } \\
\text { matemáticos percebidos no texto. }\end{array}$ & \\
\hline 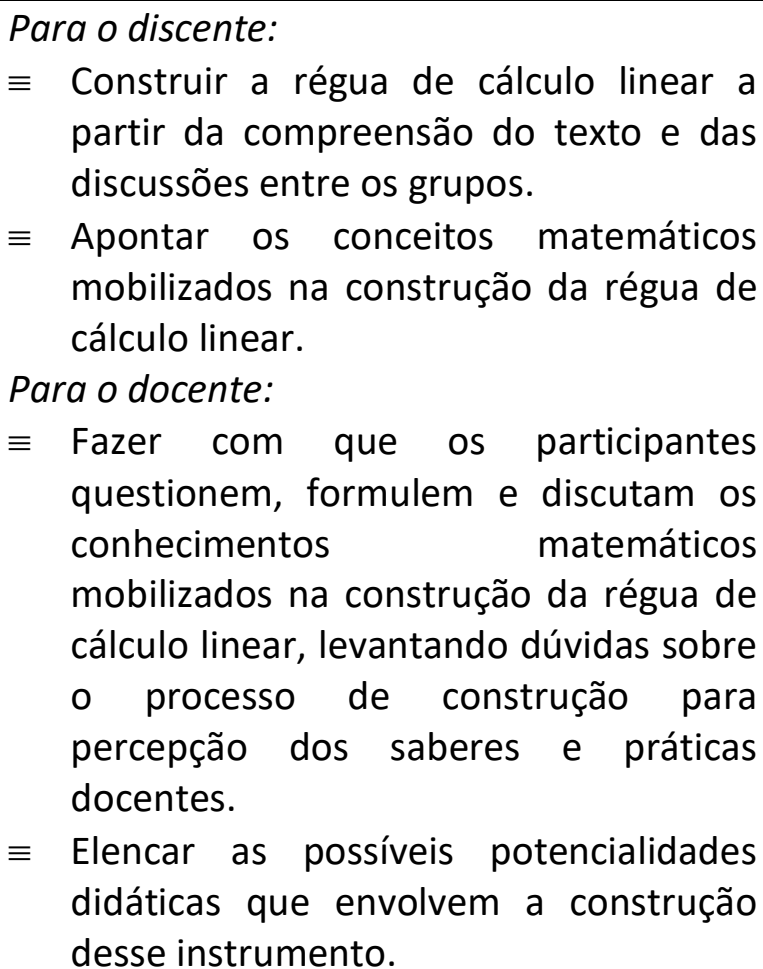 & $\begin{array}{l}\text { UNIDADE 3: A construção da } \\
\text { régua de cálculo linear } \\
3.1 \text { Construção da régua de } \\
\text { cálculo linear e manuseio do } \\
\text { instrumento produzido. } \\
\text { 3.2 Atividade sobre os conceitos } \\
\text { matemáticos percebidos ao } \\
\text { construir e manipular a régua de } \\
\text { cálculo linear elaborada para } \\
\text { efetuar multiplicações. }\end{array}$ & $2 \mathrm{~h} / \mathrm{a}$ \\
\hline
\end{tabular}

Fonte: Elaborado pelas autoras (2020).

Dessa forma, a primeira atividade consistia em conhecer brevemente o contexto histórico por trás da régua de cálculo linear, a construção e manipulação a partir do texto elaborado de acordo com as pesquisas citadas anteriormente.

Para isso, foi distribuído aos participantes um cartão de recurso (Apêndice A) Construindo as escalas logarítmicas da multiplicação -, que forneceu a descrição da régua de cálculo linear e as instruções para a construção da régua de multiplicação. Com base no cartão de recurso, foi solicitado aos participantes que identificassem, baseando-se na leitura do texto, conceitos matemáticos que dizem respeito à construção do instrumento.

Durante o desenvolvimento da atividade, a docente e a observadora responsáveis pela realização do curso, orientaram os quatro grupos, anotando e instigando os participantes com questionamentos levantados no decorrer da atividade. É interessante mencionar que ambas não interferiram nas discussões, mas sim estimularam questionamentos com base nas dúvidas dos participantes, como, por exemplo, no momento da construção da régua em que os participantes se questionaram sobre as propriedades de logaritmos, isso estava previsto no cartão de hipótese e, com base nele, foram propostas reflexões sobre a relação entre as propriedades do logaritmos e a construção da escala da multiplicação. Assim, havia o cartão 
de hipóteses (Apêndice B) - Estudo sobre a régua de cálculo linear -, que as conduziram nas possíveis dúvidas dos participantes.

Após o tempo estipulado, cada grupo expôs as questões, foi proposto que cada grupo expusesse sua compreensão sobre o cartão de recurso e como é o processo de construção da escala. Assim, questionamentos foram levantados pelos grupos, primeiramente a partir da leitura e no decorrer do curso com a construção do instrumento, gerando uma discussão sobre os conhecimentos matemáticos percebidos. Esses conhecimentos compreendidos foram usados para construir e manipular a régua de cálculo linear.

Um relatório com essas percepções foi entregue por cada grupo ao final das atividades, sendo orientado pelo guia de relatório, que foi disponibilizado às equipes, assim como o relatório individual do dia, por meio da ficha de avaliação diária. Esses materiais serviram como dados do curso. A Figura 5traz um exemplo de relatório desenvolvido pelos participantes.

Figura 5 - Relatório desenvolvido no curso.

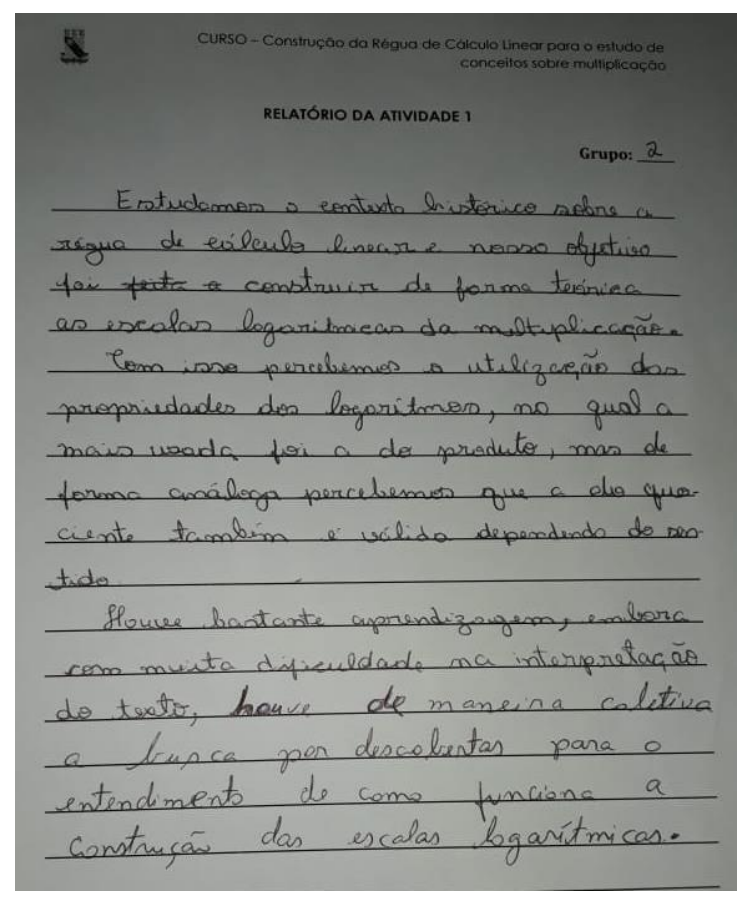

Fonte: Relatório do grupo 2 (2019).

Os relatórios desenvolvidos no decorrer do curso possibilitaram às pesquisadoras entender o processo de construção de cada grupo, as dificuldades encontradas e como eles mobilizaram os conhecimentos matemáticos de logaritmos para conseguir realizar toda a construção da escala da multiplicação da régua de cálculo linear.

\section{Uma articulação entre a construção e o manuseio da régua de cálculo linear atrelada aos saberes docentes}

Diante do exposto, busca-se apresentar a análise dos dados obtidos durante o curso de extensão universitária, a partir da perspectiva dialética que nos possibilita conhecer o contexto real a partir da esfera social, filosófica e política proporcionando a compreensão de todos os aspectos que fundamentam o complexo educacional e a relação dos sujeitos nela inseridos. Assim, utilizamos também as categorias propostas por Shulman (1986), que nos 
permitiu refletir sobre os dados logrados do curso de extensão, que tinha como objetivo principal desvelar conhecimentos construídos por meio da fabricação e manuseio da régua de cálculo linear.

Como citado anteriormente, a régua de cálculo linear é um instrumento histórico, um legado de gerações passadas que se utilizavam desse notável apetrecho para facilitar cálculos matemáticos. A relevância desse instrumento matemático para a formação docente se apresenta no fato de se constituir de um meio que possibilita a criação de novas metodologias de ensino, potencializando a ação docente e o ensino ao discente.

A luz da perspectiva dialética que nos oportuniza analisar os dados recolhidos a partir da compreensão crítica das relações sociais, podemos apresentar a fala dos sujeitos participantes do curso mostrando suas experiências, e também os conhecimentos que foram mobilizados a partir da construção e manuseio da régua de cálculo linear.

É preciso esclarecer ainda que as falas dos cursistas que serão destacadas a seguir foram coletadas a partir de um questionário aplicado após a realização do curso pela plataforma Google Formulários. Como descrito anteriormente, esse foi um dos instrumentos utilizados para coleta de dados. Partindo desse entendimento, foi possível determinar como a construção da régua de cálculo linear possibilitou o desenvolvimento de conhecimentos antes desconhecidos por parte dos docentes, como se vê nas falas dos cursistas:

Participante 1: Aprender manipulando e construindo um material que nos passa informações importantes de uma forma diferente e criativa (Participante 1, 2019).

Participante 2: No processo de construção do artefato o aluno tem mais facilidade de se apropriar do conhecimento matemático inserido na construção (Participante 2, 2019).

Assim, fazer parte do processo de construção do instrumento histórico e manusear o mesmo propicia ao sujeito o conhecimento pedagógico do conteúdo, que é destacado por Shulman (1986), essa constatação é possível por percebermos a aquisição de conceitos matemáticos que antes não eram relatadas pelos sujeitos participantes do curso. 0 processo de análise dos dados também potencializou a validação dessa constatação.

Esse conhecimento possibilita ensinar o conteúdo de formas distintas com o auxílio de recursos mais poderosos, que facilitam a compreensão de outras pessoas. A régua de cálculo linear pode ser identificada como um recurso pedagógico que potencializa o ensino de matemática e a compreensão de conceitos básicos com relação à multiplicação.

O autor, ainda, fala sobre dois outros tipos de conhecimentos, já citados anteriormente, diante dos mesmos, pode-se inferir que os participantes deixam em evidência que a construção do instrumento lhes faz conhecer novos conteúdos matemáticos e ferramentas para o ensino destes. Essa constatação fica explícita ao se observar as falas dos participantes.

Participante 3: Perceber que existem formas de trabalhar um conteúdo matemático, sem ser tradicional (Participante 3, 2019).

Participante 4: Novos métodos para trabalhar conteúdos, como multiplicação e logaritmos. Uma nova ferramenta para ampliar o conhecimento dos alunos. Uma ampliação na minha visão como professora, que devo sempre buscar novos conhecimentos para serem aplicados em sala de aula (Participante 4, 2019). 
As falas dos participantes nos remete ao conhecimento da matéria do conteúdo, em que podemos perceber que os conceitos básicos sobre o ensino de multiplicação já são do conhecimento desses participantes, mas, diante do manuseio da régua de cálculo linear, podemos afirmar que novos conhecimentos podem se desenvolver, oportunizando a compreensão da estrutura da matéria.

O reconhecimento das categorias apresentadas por Shulman (1986) traz a relevância dessas para as pesquisas em torno dos saberes docentes. Nesse cenário, no qual se evidenciam os conhecimentos construídos a partir da fabricação e do manuseio da régua de cálculo linear, gera-se outro dado importante: o valor de se trabalhar com os instrumentos históricos na formação docente, visto que estes fazem emergir saberes inegáveis à prática docente.

Ao longo das narrativas dos participantes do curso ofertado, percebe-se que estes sujeitos reconhecem a importância de se buscar recursos que auxiliem o ensino de matemática e contribuam para a formação docente.

A importância da régua de cálculo linear fica evidente nesse estudo nas respostas de alguns participantes diante da pergunta: "você acredita que a construção da régua de cálculo linear possibilitou a apropriação de conhecimentos matemáticos?" em que foi relatado que:

Participante 1: Sim. Acredito que só o fato de voltarmos o nosso olhar para uma forma de conhecimento mais dinâmica e menos tradicional, já nos permite adquirir um conhecimento melhor de determinando assunto (Participante 1, 2019).

Participante 10: Sim. Como aluno de escola pública não tinha visto operações com logaritmos e o curso fez com que eu buscasse ter um conhecimento a parte deste conteúdo, pois é necessário dentro da minha formação (Participante 10, 2019).

Dessa maneira, a construção do instrumento possibilitou novas formas de conceber o conhecimento matemático sobre logaritmos, assim, abrindo espaço para novas pesquisas sobre esse instrumento histórico, que podem trazer ao cenário da formação docente maiores contribuições didáticas para o ensino da matemática.

\section{Considerações finais}

O estudo realizado se apoia no percurso histórico do desenvolvimento do instrumento matemático para evidenciar como se consolidou a sua construção e o uso da régua de cálculo linear. Considerando a importância do instrumento em questão, realizamos um estudo para desvelar os saberes que a construção e o manuseio desse artefato propiciam à formação docente.

As categorias acerca dos saberes docentes, aqui citadas, têm como fundamento a pesquisa realizada por Shulman (1986), que apresenta categorias a respeito dos conhecimentos que se desenvolvem na mente dos professores.

Diante dos resultados, reconhecemos que a formação docente é de suma importância para o desenvolvimento de novos conhecimentos que antes eram desconhecidos pelos professores e que o uso da régua de cálculo linear proporcionou a construção de saberes aos docentes participantes do curso de extensão.

Reconhecemos, também, que, embora a relação dos docentes com os saberes que ensinam se configura como formadora da prática dos professores, ainda existe um 
distanciamento entre o que sabem os professores e o que deveriam saber para construir sua ação docente.

Estudos como este mostram a importância de discutir sobre o assunto e de apresentar recursos, como a régua de cálculo linear, para trazer contribuições no desenvolvimento de novos conhecimentos e abordagens de conceitos para os professores de matemática.

Dessa forma, as análises feitas a partir das falas dos participantes do curso de extensão universitária possibilitaram a construção deste trabalho, evidenciando a relevância de artefatos históricos para a construção de conhecimentos que contribuem para a formação docente.

É por meio dessas reflexões e evidências que se finaliza a escrita deste trabalho, em que se reitera que as discussões, aqui realizadas, foram de fundamental importância na construção de conhecimentos que contribuem para a formação e a prática docente.

\section{Referências}

ALVES, Verusca Batista. Um estudo sobre os conhecimentos matemáticos mobilizados no manuseio do instrumento círculos de proporção de William Oughtred. 2019. 155 f. Dissertação (Mestrado) Curso de Mestrado em Ensino de Ciências e Matemática, Instituto Federal de Educação, Ciência e Tecnologia do Ceará, Fortaleza, 2019.

ANDRÉ, Marli Eliza Dalmazio Afonso de. 0 que é um estudo de caso qualitativo em educação. Revista da FAEEBA- Educação e Contemporaneidade, Salvador, 2013. v.22, p. 95-103.

BARONI, Rosa Lúcia; TEIXEIRA, Marcos Vieira; NOBRE, Sérgio Roberto. História da Matemática em contextos da Educação Matemática: contribuições do GPHM. Boletim de Educação Matemática, Rio Claro, v. 25, n. 41, p.153-171, dez. 2011.

BISSI, Tiago. As potencialidades pedagógicas da História da Matemática - Uma abordagem com alunos da 8a série. Revista de História da Matemática Para Professores, Natal, p.39-57, mar. 2014.

CAJORI, Florian. A history of the logarithmic slide rule and allied instruments. New York: The Engineering News Publishing Company, 1909.

CAJORI, Florian. William Oughtred: a great seventeenth-century teacher of mathematics. Chicago: The Open Court Publishing Company, 1916.

COHEN, Elizabeth; LOTAN, Rachel. Planejando o trabalho em grupo. 3. ed. Porto Alegre: Penso, 2017. Tradução de: Luís Fernando Marques Dorvillé, Mila Molina Carneiro, Paula Márcia Schmaltz Ferreira Rozin.

D'AMBRÓSIO, Beatriz S.. Reflexões sobre a história da matemática na formação de professores. Revista Brasileira de História da Matemática, São Paulo, p.399-406, dez. 2007.

LODI, Marluce Dantas de Freitas. Pesquisa-ação: uma alternativa metodológica nos Estudos do Consumo. In: CONGRESSO NACIONAL DE ADMINISTRAÇÃO E CONTABILIDADE - ADCONT 2016, 17., 2016, Rio de Janeiro. Anais [...]. Rio de Janeiro: Congresso Nacional de Administração e Contabilidade - Adcont 2016, 2017. p. 1 - 14. 
MARTINS, Eugeniano Brito. Conhecimentos matemáticos mobilizados na manipulação das barras de calcular de John Napier descritas no tratado Rabdologiae de 1617. 2019. 104 f. Dissertação

(Mestrado) - Curso de Mestrado em Ensino de Ciências e Matemática, Instituto Federal de Educação, Ciência e Tecnologia do Ceará, Fortaleza, 2019.

MARTINS, Eugeniano Brito; PEREIRA, Ana Carolina Costa. Uma primeira descrição da obra: Rabdologiae, seu numerations per virgula ... de 1617. Boletim Cearence de Educação e História da Matemática, Fortaleza, v. 5, n. 14, p.154-166, 28 ago. 2018. Disponível em: <https://revistas.uece.br/index.php/BOCEHM/article/view/246>. Acesso em: 17 fev. 2019.

MARTINS, Eugeniano Brito; PEREIRA, Ana Carolina Costa; FONSECA, Paulo Henrique Sousa. Redescobrindo o conceito de logaritmo por meio da construção da régua de cálculo linear. Revista Eletrônica Debates em Educação Científica e Tecnológica, v. 3, p. 47-65, 2016.

MENDES, Iran Abreu; SOARES, Evanildo Costa. Logaritmos (números da razão): enfoques históricos, epistemológicos e escolares. São Paulo: Livraria da Física, 2019. (Série história da matemática para professores).

MIGUEL, Antonio. As potencialidades pedagógicas da história da matemática em questão: argumentos reforçadores e questionadores. Zetetiké, Campinas, v. 5, n. 8, p. 90-105, 1997.

MONTEIRO, Ana Maria Ferreira da Costa. Professores: entre saberes e práticas. In: Educação \& Sociedade. v. 22, no 74 2001. p. 121-142.

NAPIER, John. Rabdologiae, Seu Numerationis Per Virgulas Libri Duo: cum appendice de expeditíssimo Multiplicationes promptuario, quibus acessit e arithmeticea localis liber unus. Edinburg: Andreas Hart, 1617.

OUGHTRED, William. Circles of the Proportion and the Horizontal Instrument. London: Augustine Mathewes, 1632.

PEREIRA, Ana Carolina Costa. Aspectos Históricos da régua de cálculo para a construção de conceitos matemáticos. São Paulo: Livraria da Física, 2015. (História da Matemática para o Ensino).

PEREIRA, Ana Carolina Costa; SAITO, Fumikazu. A reconstrução do Báculo de Petrus Ramus na interface entre história e ensino de matemática. Revista Cocar, [s.I.], v. 13, n. 25, p. 342-372, fev. 2019. Universidade do Estado do Para. http://dx.doi.org/10.31792/rc.v13i25. Disponível em: https://periodicos.uepa.br/index.php/cocar/article/view/2164. Acesso em: 20 maio 2019.

PIPPA, Tania Cristina Maggioni. A função logaritmo e a régua de cálculo. 2014. 62 f. Dissertação (Mestrado) - Curso de Mestrado Profissional em Matemática em Rede Nacional, Universidade de São Paulo, São Carlos, 2014.

SAITO, Fumikazu; DIAS, Marisa da Silva. Interface entre história da matemática e ensino: uma atividade desenvolvida com base num documento do século XVI. Ciência \& Educação (bauru), [s.I.], v. 19, n. 1, p.89-111, 2013.

SAITO, Fumikazu. História da matemática e suas (re) construções contextuais. São Paulo: Livraria da Física, 2015. 
SAITO, Fumikazu. Instrumentos matemáticos dos séculos XVI e XVII na articulação entre história, ensino e aprendizagem de matemática. Revista de Matemática, Ensino e Cultura, Natal, v. 16, n. 9, p.25-47, maio 2014.

SHULMAN, Lee. Those who understand: Knowledge growth in teaching. Educational Researcher 15(2), 1986, p. 4-14.

TANONAKA, Elisa Missae. A Régua de Cálculo: Uma contribuição de William Oughtred para a Matemática. 2008. 103f. Dissertação (Mestrado em História da Ciência) - Departamento de História da Ciência, Pontifícia Universidade Católica de São Paulo, São Paulo, 2008.

TARDIF, Maurice; LESSARD, Claude; LAHAYE, Louise. Os professores face ao saber: esboço de uma problemática do saber docente. In: Teoria e Educação no 4, Porto Alegre: Pannônica, 1991. 


\section{Apêndice A - Cartão de recurso \\ Construindo as escalas logarítmicas da multiplicação}

A Régua de Cálculo Linear, construída por William Oughtred é composta por duas escalas logarítmicas, que partem do princípio das escalas logarítmicas de Edmund Gunter, do seu instrumento matemático conhecido como escala de Gunter.

A construção dessa escala de Gunter envolve a ideia de transformação de produtos de logaritmos em somas. Gunter considerou um determinado logaritmo a distância de 1 até um número de 2 a 10. Por exemplo, se for considerada a distância entre 1 e 4, ela equivale ao logaritmo de 4 . Mas, isso está diretamente relacionado com a base logarítmica que for escolhida. Para essa construção considera-se os logaritmos na base 10 que utilizamos atualmente.

Para construção das escalas logarítmicas para multiplicação, foram escolhidos os logaritmos construídos por Henry Briggs, os logaritmos na base 10, porém, somente os logaritmos primos como se observa na Tabela 1.

Tabela 1 - Logaritmos.

\begin{tabular}{|l|l|}
\hline Logaritmos & Valor \\
\hline $\log 2$ & 0,3010 \\
\hline $\log 3$ & 0,4771 \\
\hline $\log 5$ & 0,6989 \\
\hline $\log 7$ & 0,8450 \\
\hline
\end{tabular}

Fonte: Elaborada pelas autoras (2019).

Entretanto se for construída uma escala com os valores dos logaritmos exatamente como estão a escala terá um tamanho muito pequeno, impossibilitando seu manuseio. Assim, é preciso utilizar uma escala de ampliação em que a distância gráfica é maior que a distância real. 


\section{Apêndice B - Cartão de hipóteses}

\section{Estudo sobre a régua de cálculo linear}

Esse cartão de hipóteses serve para auxiliar a pesquisadora a direcionar os questionamentos dos participantes quanto a construção da escala da multiplicação e a leitura do cartão de recursos. Seguem algumas observações acerca da matemática envolvida na construção como mostra o Quadro 1 .

Quadro 1-Orientações para a pesquisadora.

\begin{tabular}{|l|l|}
\hline $\begin{array}{l}\text { Propriedade dos logaritmos de transformar } \\
\text { produto em soma e divisão em subtração }\end{array}$ & $\begin{array}{l}\text { Aqui o participante pode se questionar qual } \\
\text { propriedade dos logaritmos deve utilizar para } \\
\text { que a escala seja efetiva nos cálculos de } \\
\text { multiplicação e qual a relação das propriedades } \\
\text { com a escala }\end{array}$ \\
\hline $\begin{array}{l}\text { Relação entre medidas de comprimento e } \\
\text { valores dos logaritmos. }\end{array}$ & $\begin{array}{l}\text { Como é feita associação do comprimento do } \\
\text { segmento correspondente ao logaritmo com a } \\
\text { operação de multiplicação por meio de soma) }\end{array}$ \\
\hline $\begin{array}{l}\text { Porque necessita-se somente dos valores dos } \\
\text { logaritmos primos para construir as escalas? }\end{array}$ & $\begin{array}{l}\text { Como se obterá os demais números para } \\
\text { completar a escala? Relaçães com números } \\
\text { compostos e multiplicação }\end{array}$ \\
\hline $\begin{array}{l}\text { Há relação entre o comprimento dos logaritmos } \\
\text { na construção da régua sempre partir com 1? }\end{array}$ & $\begin{array}{l}\text { Atentar-se como os participantes iniciarão a } \\
\text { construção. Indagar quais as maneiras de se } \\
\text { construir essa escala }\end{array}$ \\
\hline $\begin{array}{l}\text { Que resultados teríamos se construíssemos os } \\
\text { logaritmos nas escalas sucessivamente sem } \\
\text { partir do 1? }\end{array}$ & $\begin{array}{l}\text { Como a multiplicação dos números ocorreria? O } \\
\text { resultado seria correto?) }\end{array}$ \\
\hline $\begin{array}{l}\text { Soma de segmentos para obter o resultado da } \\
\text { multiplicação }\end{array}$ & $\begin{array}{l}\text { Como esse processo acontece, os participantes } \\
\text { perceberam alguma aplicação para os } \\
\text { logaritmos e suas propriedades?) }\end{array}$ \\
\hline
\end{tabular}

Fonte: Elaborado pelas autoras (2019). 